\title{
COMPLETE ABSENCE OF SUPRASCAPULAR NOTCH- A CASE REPORT
}

Rekha. B. S.

1. Associate Professor, Department of Anatomy, Shimoga Institute of Medical Sciences.

\section{CORRESPONDING AUTHOR}

Rekha B. S.

Associate Professor,

Shimoga Institute of Medical Sciences

E-mail: rekhabsrangappa@gmail.com

Ph: 00919916193082.

ABSRTACT: The suprascapular notch is usually present in every scapula. Superior transverse scapular ligament is a strong fibrous band that bridges the suprascapular notch creating a foramen that gives passage to the suprascapular nerve, whereas the suprascapular vessels pass over the ligament superiorly. Suprascapular nerve supplies motor branches to the supraspinatus, infraspinatus and sensory to the rotator cuff muscles and ligamentous structures of the shoulder and acromioclavicular joint. In some cases variations of suprascapular notch is accompanied by a variation of the superior transverse scapular ligament. These variations have a role to play in suprascapular nerve entrapment. Previous work suggests that the incidence of complete ossification of the superior transverse scapular ligament varies in different populations. One of the causes of suprascapular nerve entrapment syndrome can be the complete ossification of superior transverse scapular ligament; therefore the clinician should keep this possibility in mind while dealing with patients of suprascapular nerve entrapment. But here, we are reporting a case of complete absence of suprascapular notch in a dried scapula in an adult south Indian female which could be a possible predisposing factor for suprascapular nerve entrapment syndrome.

KEY WORDS; Suprascapular notch, Supra scapular ligament, suprascapular nerve, suprascapular neuropathy.

INTRODUCTION: The scapula forms the mobile base from which the free upper limb acts. The scapula(shoulder blade), the triangular flat bone that lies on the posterolateral aspect of the thorax overlying parts of second and seventh ribs. The scapula has medial, lateral and superior borders. The superior border of scapula is marked near the junction of its medial two third and lateral one third by suprascapular notch. This is located where superior border joins the base of the coracoid process. The superior border is thinnest and shortest of three borders ${ }^{1}$.

The notch is bridged by superior transverse scapular (suprascapular) ligament which is attached laterally to the root of the coracoid process medially to the limit of the notch. The ligament is sometimes ossified, the foramen thus completed to transmit suprascapular nerve to supraspinous fossa, suprascapular vessels pass backwards above the ligament ${ }^{2}$.

Suprascapular nerve is a large branch of superior trunk of brachial plexus at Erbs point and runs an oblique course through the posterior cervical triangle towards the suprascapular notch $^{3}$. It runs laterally deep to trapezius and omohyoid enters the supraspinous fossa through the suprascapular notch inferior to superior transverse scapular ligament ${ }^{2,3}$. The six different 
types of anatomical variations of suprascapular notch have been reported ${ }^{4}$. The documented variations of superior transverse scapular ligaments include calcification, partial or complete ossification and multiple bands. In the diagnosis of suprascapular nerve entrapment syndrome these variations in the anatomy of the superior transverse scapular ligament sometimes feature in the hierarchy of possible etiologic factors. ${ }^{3,5}$ Complete ossification of superior transverse scapular ligament thus converting notch into a foramen has been described by various authors. Complete absence of suprascapular notch has been described among Nigerians in male scapula ${ }^{6}$. We are describing a complete absence of suprascapular notch in a dried scapula of an adult south Indian female, which could be a possible cause of suprascapular nerve entrapment.

A CASE REPORT: During routine dissection class room studies a left scapula without suprascapular notch was found. Normal parameters of the bone were studied using sliding calipers.

\section{TABLE No. 1}

\begin{tabular}{|l|l|}
\hline $\begin{array}{l}\text { Length of the superior border from the base of the coracoid process to } \\
\text { the medial angle }\end{array}$ & $6 \mathrm{cms}$ \\
\hline Lateral border from infraglenoid tubercle to the inferior angle & $13 \mathrm{cms}$ \\
\hline Medial border from medial angle to inferior angle & $13 \mathrm{cms}$ \\
\hline Weight of scapula & $48 \mathrm{grams}$ \\
\hline
\end{tabular}

DISCUSSION: The suprascapular notch is usually present in every scapula, although several morphological variations and classification of the suprascapular notch were reported in various populations.

It is commonly bridged by superior transverse scapular ligament ${ }^{1}$. The ligament is sometimes ossified the foramen, thus completed transmits suprascapular nerve to supraspinous fossa ${ }^{2}$.Various factors have been identified as being causes of suprascapular nerve entrapment including the variations in the suprascapular notch along with the variations of suprascapular ligament ossifications.

The suprascapular notch is frequently bridged by a bone rather than a ligament converting it into a foramen in some animals. But in humans, the conversion of scapular notch into a foramen as a result of ossification of the suprascapular ligament was found in $60(5 \%)$ scapulae by Poirier and Charpy (1911).

In 133 finish scapulae studied by Kajava (1924) the foramen was present only twice (1.5\%). Vallois (1925) found the foramina to occur 13 times in 200(6.5\%) . Gray (1942) found foramen in 73 of 1151 scapulae (6.34\%), no suprascapular foramina were found in 87 Indian scapulae. 4

Rengachary et al (1979) have reported 6 different types of anatomical variations in suprascapular notch. They also supported that these anatomical variations of suprascapular notch and suprascapular ligament constitute potential predisposing factors to suprascapular nerve entrapment ${ }^{3}$. However suprascapular nerve entrapment syndrome has also been described amongst Nigereans. They also reported that this could be possible cause of suprascapular nerve entrapment ${ }^{5}$. In the present case report, at the place where the 
suprascapular notch should have been present, we found that the bone was thinner and more translucent than in the other parts.

It could be postulated that complete absence of the suprascapular notch may also be one of the predisposing factor for suprascapular nerve entrapment syndrome.

Suprascapular nerve entrapment may occur at any point along its course. The absence of the suprascapular notch in our subject suggests the possibility of compression of the suprascapular nerve by the superior transverse scapular ligament on the superior border of the scapula. This compression may be pronounced when superior transverse ligament is ossified. With entrapment of the nerve, atrophy of both the infraspinatus and supraspinatus muscle may occur6. Black KP and Lombardo JA reported the paralysis, weakness, numbness and burning sensations in the hand may be initial symptoms later may be only weakness of abduction and external rotation as is seen in suprascapular nerve injury? ${ }^{7}$. Thus the present study draws an attention to an absence of suprascapular notch; a regular anatomical feature of scapula can also lead to clinical condition rather than just ossification of the superior transverse scapular ligament

CONCLUSION: This anatomical information is important in the management of suprascapular nerve entrapment neuropathy or interventional procedure of the suprascapular nocth and rotator cuff tears as well as injury to suprascapular nerve in arthroscopic shoulder procedures. But to consider this variation as an abnormality we feel further research on coracoid process morphology and morphometry, mainly the vertical height in presence or absence of suprascapular notch is necessary.

\section{REFERENCES:}

1. Moore KL, Dalley AF. Clinical oriented Anatomy. 5th edition, Williams \& Wilkins Lippincott, 2006. pp730-732.

2. Standring S. Gray's Anatomy. The Anatomical Basis of Clinical Practice. 39th edition. Elsevier Churchill Livingstone; 2005. pp-821.

3. Poberaj B, Kovacic L. The presence of suprascapular neuropathy in rotator cuff tears. International Journal of Shoulder Surgery 2007; 1:58-63.

4. Rengachary SS, Neff JP, Singer PA, Brackett CF. Suprascapular nerve entrapment neuropathy: A clinical, anatomical and comparative study, Part 1, Clinical study. Neuro Surgery. 1979; 5:441-6.

5. Mohd.AK. Complete Ossification of the Superior Transverse Scapular Ligament in an Indian Male Adult. International Journal of Morphology, 2006, 24(2); 195-196.

6. David A.Ofuson, Raymond A Ude. Cristina U.Okwuonu, and Olamide A Adesanya. Complete absence of the suprascapular notch in Nigerian scapula:A possible cause of suprascapular nerve entrapment. International journal shoulder surgery Oct-Dec; 2(4); 65-66, 2008.

7. Black KP and Lombardo JA. Suprascapular nerve injuries with isolated paralysis of the infraspinatus.Am J Sports Med,1990,18;225-8.[PubMed]

\section{FIGURE No.1}




\section{CASE REPORT}

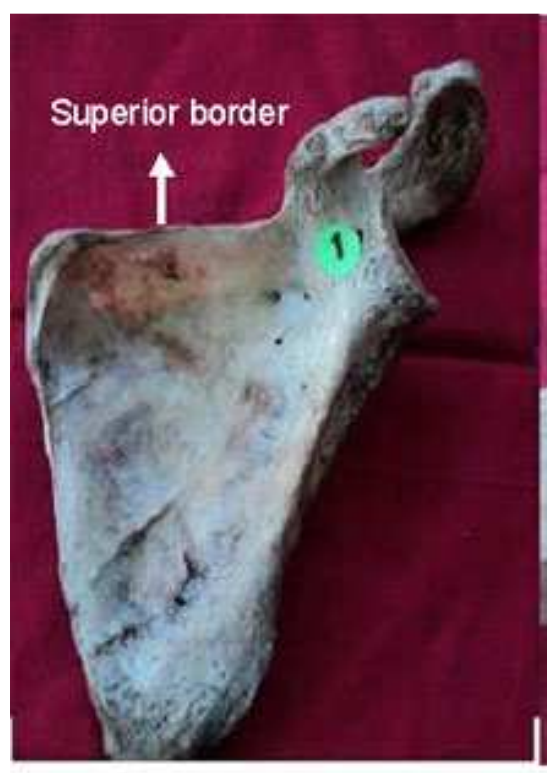

Anterior view

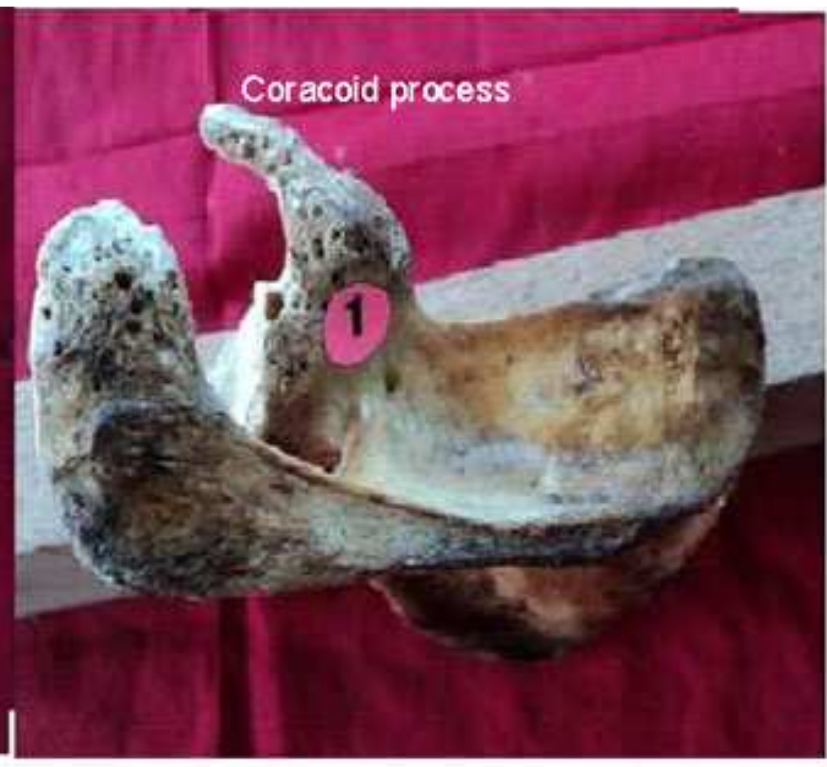

Superior view 